The biological synthesis of the polysaccharides is effected by two phosphorylases, one synthesizing 1,4-linkages, the other 1,6-linkages, the starting material being in both cases glucose-1-phosphate ${ }^{1,2}$. The first enzyme, studied by Hanes and others, when acting alone, synthesizes unbranched saccharides of the amylose type. This enzyme is called the ' $P$. enzyme' by Haworth. Bernfeld, Meyer and their coworkers use the designation 'phosphorylase', whereas the enzyme synthesizing 1,6.linkages is termed 'isophosphorylase'. This enzyme seems, on the whole, to be identical with the ' $Q$-enzyme' of Haworth and the 'branching factor' of Cori.

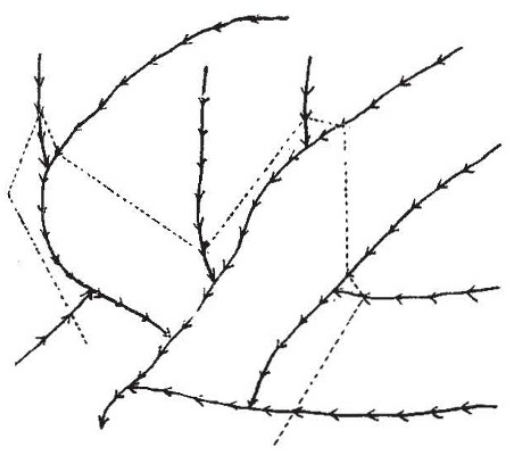

Part of a ramifled molecule of the amylopectin-glycogen type. Parts outside dotted line are split off as maltose by $\beta$-amylase

When a polysaccharide is formed through the simultaneous action of both enzymes, one may imagine two extreme cases: one which has been emphasized by Bernfeld ${ }^{3}$, Meyer ${ }^{4}$ et al. is that of reversible synthesis, when the macromolecule is in contact with the enzymes for so long a time that its final state is one of equilibrium; the other extreme is a completely irreversible synthesis, where the growth of the molecules is so rapid that the reverse reaction is negligible.

We believe it possible to decide which of these two possibilities is most closely approached by studying the action of $\beta$-amylase on the macromolecules. This enzyme attacks only end chains, splitting off glucose units in pairs as maltose ${ }^{5}$. Now the fraction of the total number of glucose residues that can be split off by $\beta$-amylase is a quantity characteristic of the polysaccharide and can be experimentally determ. ined; we shall denote it as $\zeta$.

A few years ago, we derived a relation between $\zeta$ and $\beta$ that should hold for the case of irreversible synthesis, supposing that the $\beta$-amylase cuts off as much as possible from the end chains without breaking any 1,6-links :

$$
\begin{gathered}
\zeta_{2(\mathrm{irr})}=0.6557-1.4371 \beta+0.3151 \beta^{2}+ \\
0.3154 \beta^{3}+\ldots
\end{gathered}
$$

Now we have derived the corresponding formula for the case of a macromolecule in its equilibrium state (reversible synthesis) :

$$
\begin{aligned}
\zeta_{2(\mathrm{rev} .)}= & 0.5-1.25 \beta+0.625 \beta^{2}+ \\
& 0.3125 \beta^{3}+\ldots .
\end{aligned}
$$

In both cases it has been assumed that there is no serious steric hindrance, so the probabilities for the formation (or breaking) of 1,4- and 1,6-links have the same ratio in all parts of the molecule.

If these formulæ are applied to amylopectin with $\beta=0.065$ we find $\zeta_{2(\mathrm{irr} .)}=0.58$ and $\zeta_{2 \text { (rev.) }}=0.43$, whereas the experimental values range between 0.55 and 0.62 . On the other hand, for glycogen with $\beta=$ 0.09 we find $\zeta_{2(1 \mathrm{rr} .)}=0.53$ and $\zeta_{2(\mathrm{rev} .)}=0.39$, whereas $\zeta_{\exp }=0 \cdot 35-0 \cdot 45$. (A higher value which was occasion ally found by Meyer may be due to degradation because of the rough pretreatment of the sample.)

Thus it appears that amylopectin is certainly not in an equilibrium state of the type assumed by Bernfeld and Meyer, although this might be approx imately true for glycogen. Starch seems to be formed chiefly by a one-way process and is stored in the plant for a long time, whereas glycogen is formed as a reserve for short times of delivery and is continuously changing its amount in the animal (and yeast) organisms.

It seems possible that, under certain conditions, the organisms can form glycogen so rapidly that there is no time for equilibrium. In such samples of glycogen, the relation between $\beta$ and $\zeta$ would deviate from (2) and tend toward (1).

Details of these calculations will be published in Acta Chemica Scandinavica.

K. MYRBÄCK

L. G. SILLÉN

Chemical Laboratory,

University,

Stockholm.

Jan. 4.

${ }^{2}$ Kerr, R. W. " "Chemistry and Industry of Starch" (Academic Press, Inc., New York, 1944).

2 Meyer, K. H., "Advances in Enzymology", 3, 109 (1942).

${ }^{3}$ Bernfeld, P. and Mentémédian, A., Nature, 162, 297, 618 (1948); Helv. Chim. Acta. 81. 1724, 1735 '(19+8).

4 Meyer, K. H., et al., Helv. Chim. Acta, 31.1536 (1948).

s Myrback, K., "Advances in Carbohydrate Chemistry", 3, 251 (1948).

"Sillén, L. G., and Myrbăck, K., Svensk kem. tid., 55, 294, 311, 354 (1943); 56, 60 (1944).

\title{
Cephalopods from Local Waters at the University of Istanbul
}

THROUGH the kindly co-operation of the British Council, I have been enabled to examine the local collection of Cephalopods of the University of Istan. bul, which was sent to me by Prof. Curt Kosswig, of the University's Zoological Depa tment.

It comprises eleven specimens, preserved in formalin solution :

\section{Name}

Eledone moschata (Lamarck)

* Sepietta neglecta? (Naef)

Sepia elegans (Orbigny)

Alloteuthis media (Linné)

$\dagger$ Octopodoteuthis sicula (Rüppell)

* Probably S. neqlecta.

t Both fins had had about a third of the area farthest from the body cut off.

Of these five species, my regional records of the distribution of Cephalopods mention, as having been encountered in this region, only Octopodoteuthis sicula (Rüppell) ; locality, east of Rhodes.
7 Pandora Road,
London, N.W.6.
Sept. 11.

Bassett Dighy 